\title{
O livro de artista, o colecionador e a coleção no museu: um itinerário intersubjetivo da coleção de livros de artista de Paulo Herkenhoff no Museu de Arte do Rio
}

\author{
The artist's book, the collector and the collection at the museum: an an intersubjective \\ itinerary of Paulo Herkenhoff's artist's books collection at the Museu de Arte do Rio
}

\author{
Andréa da Silva Barboza \\ Mestre em Biblioteconomia pela UNIRIO. \\ Bibliotecária na Fundação Biblioteca Nacional. \\ E-mail: deafurg@gmail.com
}

\author{
Gustavo Silva Saldanha \\ Doutor em Ciência da Informação pelo IBICT/UFRJ. \\ Professor Adjunto da Universidade Federal do Estado do Rio de Janeiro - UNIRIO. \\ E-mail: saldanhaquim@gmail.com
}

\begin{abstract}
Resumo
Este trabalho tem como objetivo discutir a condição da coleção de livros de artista conformada por Paulo Herkenhoff ao longo de sua trajetória subjetiva (nas mãos do colecionador) e duplamente intersubjetiva, ou seja, de um lado, reconhecida nas mãos do donatário (uma vez doada à biblioteca do Museu de Arte do Rio em 2013), de outro lado, apropriada pela experiência do olhar do profissional bibliotecário diante dos itens. Para a realização do estudo, apresentamos a instituição Museu de Arte do Rio em sua história, sua missão e sua arquitetura. Em seguida, realizamos de uma breve cronologia biobibliográfica de Paulo Herkenhoff. No plano metodológico, como estudo exploratório e qualitativo, o trabalho recorre às fontes primárias e bibliográficas, de fundo institucional, biográfico e teórico, incluindo a entrevista com o próprio colecionador e a consulta à fundamentação teórica do livro de artista, bem como à literatura biblioteconômica dedicada à teorização das práticas de preservação e de organização do conhecimento de coleções especiais. Como resultados, o estudo evidenciou as dimensões complexa e híbrida do livro de artista em suas diferentes figurações espaço-temporais, do plano conceitual ao plano institucional-aplicado, tendo como margem empírico-subjetiva a necessidade de reconhecimento da trajetória do colecionador como efeito central para as decisões de práticas institucionalizáveis sobre o livro de artista. As conclusões apontam para o dilema entre o local de guarda e as tipologias descritivas como instâncias ainda em aberto, reconhecidas como categorias tão complexas quanto emergentes para o debate sobre o livro de artista no campo.
\end{abstract}

Palavras-chave: Livro de artista. Coleções especiais. Paulo Herkenhoff. Museu de Arte do Rio.

\begin{abstract}
This paper discussed the condition of the collection of artist books formed by Paulo Herkenhoff throughout his subjective trajectory (in the hands of the collector) and doubly intersubjectivite, that is, on the one hand, recognized in the "hands of the donator" (once donated to the library of the Rio Art Museum in 2013), on the other hand, appropriated by the experience of this professional on the items. For this study, we presented the institution Museum of Art of Rio in its history, its mission and its architecture, followed by a brief biographical chronology of Paulo Herkenhoff. The methodological approach, as an exploratory research, used primary and bibliographic sources, including the interview with the collector himself and the reference to the theoretical basis of the artist's book, as well as to the library literature devoted to the theorizing of preservation practices and organization of the knowledge of special collections. As a result, the study demonstrated the complex and hybrid condition of the artist's book in its different space-time dimensions, from the conceptual plane to the institutional plane, having as empirical-subjective margin the need for recognition of the collector's trajectory. The conclusions pointed to the dilemma between the place of custody and the descriptive typologies as instances still open, recognized as categories that are complex and emergent for the debate about the artist's book in the field.
\end{abstract}

Keywords: Artist's book. Special Collection. Paulo Herkenhoff. Museu de Arte do Rio.

InCID: R. Ci. Inf. e Doc., Ribeirão Preto, v. 8, n. 2, p. 176-191, set. 2017/fev. 2018.

DOI: 10.11606/issn.2178-2075.v8i2p176-191 


\section{A rota dos livros de artista: uma introdução ao dilema}

A história dos registros do conhecimento é contada a partir de seus diferentes suportes. Transgredir os limites da oralidade e representar o conhecimento através da escrita atribuindo formas distintas de fixação dos saberes são ações que fazem com que esses suportes sejam vistos como objetos míticos, símbolos de poder e de culto, manifestações da arte e instrumentos de comunicação.

Nas coleções de bibliófilos estão presentes os mais diferentes tipos de registros, como obras raras, primeiras edições, exemplares autografados e livros de artista. Este último, objeto de estudo desta pesquisa, possui características particulares. Diferente dos demais, o livro de artista apresenta, algumas vezes, características semelhantes a um objeto de arte, podendo ser chamado de livro objeto. Entre as diferentes tipologias aproximadas existem ainda: livro ilustrado, livro de arte, arte-livro, livro-obra, além da existência de outras nomenclaturas que variam de acordo com suas especificidades e com a posição deste ou daquele teórico. Nesta pesquisa utilizaremos o termo "livro de artista", com sentido abrangente, que contempla todas as diferentes tipologias de tal categoria.

Inovador, com formatos e conteúdos distintos, o livro de artista transcende a intenção de informar através do texto e torna-se uma obra de arte, podendo comunicar através de linguagem não verbal, utilizando-se de imagens, diferentes formas e texturas. De acordo com Plaza (1982, p. [1]), o livro de artista "é criado como um objeto de design, visto que o autor se preocupa tanto com o 'conteúdo' quanto com a forma e faz desta uma forma-significante”. São objetos informacionais cuja intencionalidade está em transmitir uma experiência artística e, por isso, podem ultrapassar o formato de códice tradicional do livro e trazer uma apresentação que se preocupa com a estética e o conceito do livro, bem como com as visões estético-políticas do autor.

O livro de artista ascende como uma forma de ruptura com o mercado da arte, que até o período da Arte Moderna restringia o acesso às obras a um pequeno grupo. Ao contrário das obras de arte que são apresentadas dentro de galerias e museus, o livro de artista tem o objetivo de proporcionar que a arte ultrapasse as barreiras que a retém em seus locais convencionais, chegando diretamente ao público.

Para Fabris (1988), o livro de artista surge do encontro entre arte e literatura, numa referência aos livros ilustrados que deram início a esta nova 'categoria' de arte. A pesquisadora 
cita três elementos que devem ser levados em conta no processo de afirmação do livro de artista “1 - a renovação da concepção do livro em geral; 2 - o papel das vanguardas editoriais que, ao produto anônimo da indústria editorial, opõe "criações pessoais"; 3 - o surgimento de editoras especializadas".

Antonio Dias apud Espínola (2004, p. 25-26) faz uma crítica à limitação na tiragem do livro de artista, o que dificulta a divulgação do mesmo. Para ele "fugir dos padrões industriais em série significa reduzir a tiragem e aumentar seu custo, ainda que em sua elaboração sejam utilizados materiais de baixo custo, como é o caso de The Social Strategy [...] confeccionado em papelão de sapateiro".

Espínola (2004) nos atenta para o fato comum da não veiculação de tais obras, afirmando que isto "significa o próprio confinamento da arte" (ESPÍNOLA, 2004, p. 26). Ele coloca, por exemplo, o formato de sanfona como um solucionador deste problema devido à facilidade de sua reprodução e consequentemente disseminação.

Para Bento (2008), o hibridismo da arte contemporânea pôs um fim à classificação e à conceituação da arte comuns até o século XIX. Ele questiona a limitação do livro em formato de códice para suportar as novas "demandas sonoras e visuais da poesia pós-moderna" (BENTO, 2008, p. 1) e descreve que o declínio do livro como suporte informacional veio com o início de novos meios de comunicação mais sucintos, objetivos e visuais, como o jornal e, posteriormente, a televisão.

Embora as primeiras manifestações do livro de artista datem do século XIX, seu ápice ocorreu em meados do século XX, no início do Pós-Modernismo. No Brasil, de acordo com Monteiro (2011), o livro de artista surge ligado à poesia neoconcreta da década de 1960. Tal obra se manifesta como um espaço para a arte transcender as paredes tradicionais dos museus. Os livros elaborados em parceria pelo poeta concretista Augusto de Campos e o artista Julio Plaza são exemplos da união entre poesia e arte através do concretismo e da semiótica.

O artista Wladimir Dias-Pino foi um dos grandes precursores da poesia concreta na década de 1960 e pioneiro na produção de poema processo, em 2016, teve seu trabalho exposto no Museu de Arte do Rio (MAR), na exposição individual intitulada $O$ poema infinito de Wlademir Dias-Pino. Na década de 1970, há um grande aumento na produção de livros de artista cujos temas passam a contemplar política, fotografia, poesia etc. Como uma tendência conceitual, no final daquela década, assim como os demais tipos de obras conceituais, os livros 
de artista sofrem a redução de procura por suas produções. Com o desinteresse do mercado editorial, os livros de artista passam a ser elaborados de forma artesanal, procurando expressar, a partir da década de 1980, uma experiência mais sensorial.

Seja através do mercado editorial ou da confecção artesanal, a premissa principal do livro de artista é transpor as vitrines de galerias de exposição e chegar diretamente ao público. Os artistas perceberam no livro um suporte passível de produção em massa e de baixo custo que possibilitava o alcance de um público maior, irrestrito aos tradicionais espaços expositivos da arte. Por estar ligado a um período artístico tão recente e permanecer uma prática vigente, ainda há muitas questões que permeiam esta temática, como os aspectos de definição e de armazenamento das obras.

Alguns teóricos se preocupam com a classificação do livro de artista, analisando a obra em suas diferentes formas de apresentação, como é o caso de Silveira (2008), que busca problematizar a categorização do livro de artista reunindo a opinião de alguns dos principais teóricos. Silveira (2012) traz uma abordagem para a identificação do livro de artista através da reflexão sobre o que é este objeto (tentativa de definição) e os diferentes tipos de manifestações (formatos da obra) em que ele pode se apresentar, ou seja, em suas palavras, encontramos nesse cenário

o livro de artista propriamente dito (geralmente uma publicação), o livro-objeto (que o precedeu historicamente e ainda o acompanha), o livro-obra (muito mais uma qualidade, uma adjetivação, do que um produto autônomo), além de - por que não? os livros e não-livros escultóricos, certos experimentos digitais, algumas instalações e todo um mundo de objetos ou situações que determinaremos como sendo "livroreferentes" (SILVEIRA, 2012, p.52).

Entre os teóricos apresentados por Silveira (2008), salientamos a categorização realizada por Clive Phillpot, bibliotecário e curador do MoMa. Phillpot divide o livro nas categorias

Livro - Coleção de folhas em branco e/ou que portam imagens, usualmente fixadas juntas por uma das bordas e refiladas nas outras para formar uma única sucessão de folhas uniformes.

Livro de arte - Livro em que a arte ou o artista é o assunto.

Livro de Artista - Livro em que um artista é o autor.

Arte do livro - Arte que emprega a forma do livro.

Livro-obra - Obra de arte dependente da estrutura de um livro.

Livro objeto - Objeto de arte que alude à forma de um livro. (PHILLPOT, 1982 apud SILVEIRA, 2008, p. 47-48).

Julio Plaza, além de artista e autor de livros de artista, é também um dos principais teóricos do tema. Plaza $(1982,[1,2])$ elaborou um quadro sinóptico em que divide o livro de 
artista em dois grandes eixos:

a) Analógico-sintético-ideogrâmico, com as categorias: livro ilustrado, poema-livro, livropoema, livro objeto e livro-obra; e

b) Analítico-discursivo-lógico, com as categorias: livro conceitual, livro-documento e livro intermedia.

A principal diferença que observamos nas categorizações de Phillpot e Plaza é que enquanto Phillpot considera livro de artista apenas as obras que apresentam relação com a forma do livro tradicional, Plaza se desprende da forma tradicional e compreende como livro de artista obras que muitas vezes não possuem qualquer relação com livros tradicionais, como é o caso das obras intermedia. A ótica de cada teórico reforça a necessidade de um estudo aprofundado para a realização do tratamento deste tipo de acervo.

Diante da contextualização lançada até o momento, esse trabalho se propõe reconhecer e discutir a trajetória da coleção Paulo Herkenhoff de livros de artista em sua transposição do espaço-tempo doador à dinâmica espaço-temporal do Museu de Arte do Rio (MAR). Abordaremos a história do doador e do donatário, apresentando as questões que surgiram em virtude da doação e as medidas tomadas para saná-las. Reconheceremos ainda a vivência do desafio do acolhimento dessas obras até seu destino final dentro da instituição e as medidas tomadas para seu tratamento.

A partir do contato direto com a coleção, verificamos uma série de questões a serem resolvidas, partindo da necessidade sócio institucional da condição de um acervo a tratar e disponibilizar para o público. A solução mais prudente para a resolução crítica dos dilemas da experiência empírica foi a realização de uma pesquisa que conciliasse o discurso teórico que aborda o livro de artista e a experiência institucional do pensamento biblioteconômico e de suas ferramentas. O presente trabalho é, pois, resultado da dissertação desenvolvida no Mestrado Profissional em Biblioteconomia da Universidade Federal do Estado do Rio de Janeiro (UNIRIO) e teve como objetivo trazer para o campo um tema que é predominantemente explorado pela área de artes, realizando, assim, uma pesquisa focada em entender esse tipo de acervo, suas (tentativas de) definições e, então, poder executar a catalogação descritiva da forma mais coerente, (re)discutindo os padrões biblioteconômicos. 


\section{O homem e sua coleção: silhuetas do doador e sua dimensão subjetiva}

No seio de uma família de classe média, nasceu em 1949, na cidade Cachoeiro de Itapemirim, interior do Espírito Santo, Paulo Estellita Herkenhoff Filho. Na infância, em vez de pré-escola, sua mãe o matriculou em uma escolinha de arte. Herkenhoff cresceu dentro da escola fundada pelos avós paternos, onde começou a trabalhar aos dez anos de idade e aos quatorze ou quinze anos passou a lecionar. Ao completar dezoito anos, participou de programa de intercâmbio nos Estados Unidos (HERKENHOFF FILHO, 2005).

No ano de 1969, Herkenhoff se transferiu para a cidade do Rio de Janeiro, onde se formou bacharel em direito pela Pontíficia Universidade Católica do Rio de Janeiro (PUC-Rio) em 1973. Durante a graduação, Herkenhoff não se limitou às disciplinas oferecidas na grade curricular do curso de direito. Ele aproveitou a oportunidade de estar em uma universidade que oferecia uma série de cursos que lhe interessavam e cursou disciplinas na área de ciências sociais e estética. Incentivado por seu mestre, Ivan Serpa, Herkenhoff se aventurou pela arte expondo alguns trabalhos (HERKENHOFF FILHO, 2005).

Após a conclusão da graduação, realizou mestrado em direito comparado na New York University. Ao regressar ao Brasil, passou a ministrar aulas na PUC e foi trabalhar em um órgão da Secretaria da Justiça do Estado do Rio de Janeiro, do qual foi demitido devido ao seu vinculo como professor universitário de direito constitucional (HERKENHOFF FILHO, 2005).

Em 1983, Herkenhoff pediu demissão do cargo de professor da PUC e de um escritório de advocacia no qual trabalhava, passando a atuar como chefe de gabinete da FUNARTE. Neste mesmo período recebeu uma proposta de uma empresa no Iraque para atuar na área de Direito, da qual declinou para poder permanecer no Rio de Janeiro e se dedicar profissionalmente à arte.

Ainda na FUNARTE, foi convidado para o cargo de assessor da presidência da Fundação Biblioteca Nacional (FBN) em 1991, período em que Affonso Romano de Sant'anna ocupava o cargo de presidência. Permaneceu neste cargo até 1993, quando foi convidado a dirigir o Museu de Arte Moderna do Rio (MAM) (HERKENHOFF FILHO, 2005).

Ao chegar ao MAM, encontrou o museu com grandes prejuízos decorrentes do incêndio de 1978. Com a missão de reerguer o museu, se dedicou ao desenvolvimento da coleção sob a perspectiva de que um 
museu é uma instituição encarregada de coletar bens culturais; o museu tem o dever de registrar, documentar, catalogar e preservar esses bens; é tarefa do museu estudar esses bens e devolver à sociedade através de exposições, publicações, educação e outras atividades de comunicação. Isso foi a grande lição de museologia, ou seja, é um conjunto de responsabilidades, não de privilégios. Privilégios você constrói pessoalmente, mas primeiro está a responsabilidade. (HERKENHOFF FILHO, 2005).

Ao longo de seu percurso profissional, Herkenhoff sempre manteve proximidade com a arte, mesmo na época em que atuava como advogado através de cursos, disciplinas acadêmicas, círculo de amizades e trabalhos que acabavam convergindo em relações com o universo artístico. Um exemplo é o seu trabalho no escritório Bastian Pinto \& Taunay, onde foi incumbido de tratar os assuntos referentes à Fundação Castro Maia, o que demonstra como esteve sempre articulando relações com curadores e museólogos.

Em seu percurso pela arte, Herkenhoff foi artista, diretor cultural, chefe de gabinete, curador, crítico e autor de vários livros sobre arte, bem como de livros de artista. Ele oniciou sua carreira sendo um dos pioneiros da videoarte no Brasil na década de 1970. Posteriormente, abandonou a carreira na área de Direito para se tornar um dos mais destacados pesquisadores e curadores de arte brasileira.

Em sua atuação como diretor do Museu Nacional de Belas Artes do Rio de Janeiro (MNBA) e curador do MAM, do Museu de Arte Moderna de Nova Iorque (MoMA) e da Fundação Eva Klabin, entre outros, Herkenhoff foi ganhando notoriedade e cada vez mais se destacando no meio artístico. Como assessor da presidência na FBN, entre suas atividades, se ocupou de ampliar o acervo e dar visibilidade ao mesmo através de exposições. Na década de 1990, assumiu a curadoria geral da XXIV Bienal de São Paulo. No transcurso dessa pesquisa, Herkenhoff ocupava o cargo de diretor cultural e curador do MAR.

Como grande conhecedor da arte nacional e internacional, Herkenhoff desenvolveu ao longo dos anos uma grande coleção de livros, entre os quais, livros de artista. Em entrevista à Folha de São Paulo, em 2013, às vésperas da inauguração do MAR, Herkenhoff declarava sua intenção de desenvolver uma coleção de livros de artista no museu.

Pelas instituições por onde passou, Herkenhoff sempre demonstrou o interesse pelas bibliotecas, nas quais deixou grande contribuição através da doação de acervos, como foi o caso na biblioteca do MNBA, do MAM e a Biblioteca Nacional (BN). Em 2013, uma parte de sua coleção pessoal de livros de artista foi doada ao MAR. Esta doação instigou a equipe da biblioteca a realizar pesquisas sobre livro de artista devido à necessidade de abordagens teóricas e metodológicas específicas para o tratamento dessa coleção. 


\section{O museu de arte do Rio: as curvas do donatário, uma primeira dimensão intersubjetiva}

No dia primeiro de março de 2013 foi inaugurado, na cidade do Rio de Janeiro, o Museu de Arte do Rio. Com a missão de proporcionar conhecimento em arte e a experiência do olhar com ênfase na formação de acervo e na educação, o MAR apresentava a proposta de promover a cultura através da educação.

Situado na Praça Mauá, o MAR está instalado em dois prédios bastante distintos no plano da arquitetura: o Palacete Dom João VI, prédio tombado que possui um estilo modernista, e o prédio da Escola do Olhar, que apresenta uma arquitetura contemporânea. Os prédios são unidos por uma cobertura fluida em forma de onda, uma característica arquitetônica marcante do complexo, e interligados por uma passarela que permite o acesso de um prédio a outro, a partir do $5^{\circ}$ andar da Escola do Olhar.

Partindo da premissa de que para chegar até a arte é preciso passar pela educação, o museu proporciona uma experiência física e simbólica através do seu sistema de circulação. Ao chegar ao MAR, para acessar o pavilhão de exposições, situado no Palacete Dom João VI, o visitante precisa subir até o $5^{\circ}$ andar da Escola do Olhar e percorrer a passarela que interliga os dois prédios. Dessa forma, cada visitante percorre primeiramente o prédio que simboliza a educação, antes de adentrar o prédio que simboliza a arte.

O Palacete Dom João VI compreende oito salas de exposições, distribuídas entre seus quatro andares. As exposições são, em geral, mostras de curta duração que permanecem em média por quatro meses. O prédio da Escola do Olhar é um espaço de formação continuada que busca atender aos professores da rede pública de ensino. Com seis andares, a escola se divide em salas administrativas, auditório, restaurante, terraço e salas de aula. As salas de aula e o auditório são utilizados para oferecer cursos, workshops, palestras, seminários etc. Entre as atividades realizadas na Escola do Olhar, além dos programas educativos oferecidos pela gerência de educação do MAR, existem experiências em parceria com universidades e instituições, como seminários e aulas.

O prédio da Escola do Olhar fica à esquerda de quem o observa de frente, do lado direito o Palacete Dom João VI. Os prédios são interligados pela cobertura fluida em forma de onda e unidos através de uma passarela que aparece abaixo da cobertura. Entre os dois prédios, há uma praça onde é realizada a recepção e acolhimento aos visitantes. Nessa praça, ficam localizados 
os serviços de café, loja e bilheteria.

Em meio às propostas do MAR, está o compromisso com a formação de acervo. Em razão disso, ele alimenta as seguintes coleções:

- Coleção museológica - pinturas, esculturas, indumentárias, peças de antiguidade, objetos relacionados à história do Rio de Janeiro etc.;

- Coleção arquivística - fotografias, cartões postais, certidões, cadernos de anotações, material audiovisual, folders, convites de exposições, cartazes etc; e

- Coleção bibliográfica - livros, periódicos, catálogos de exposição, material audiovisual, livros de artista etc. (MUSEU DE ARTE DO RIO, 2015)

As peças museológicas ficam armazenadas na reserva técnica, situada no Palacete Dom João VI, em condições de temperatura e umidade controladas, sob a guarda da equipe de museologia. A reserva técnica é uma sala projetada para armazenagem de diferentes tipos e formatos de acervos de arte como pintura, escultura, etc. O processo de catalogação desse acervo teve início em abril de 2015, quando a adaptação da planilha de catalogação do acervo museológico foi concluída dentro do Sistema Pergamum.

As coleções arquivística e bibliográfica são armazenadas na biblioteca, situada no prédio da Escola do Olhar, observando as necessidades de controle de temperatura e umidade dos itens que requerem maiores cuidados, sob a guarda da bibliotecária responsável pelo acervo. A biblioteca possui dois diferentes tipos de acesso ao acervo, dividindo-se, no âmbito da disponibilidade de consulta, em livre acesso e acesso restrito. Embora todos os acervos estejam disponíveis para o público externo, o acesso restrito é limitado a um número menor de consulentes por vez e exige agendamento prévio. As obras mantidas em acesso restrito possuem controle de umidade e temperatura, devido a suas características de raridade e necessidade de preservação. As obras de livre acesso são armazenadas no salão de leitura, onde permanecem à disposição dos usuários.

Voltando ao período de inauguração do MAR, a estrutura de guarda de acervo não estava concluída quando o museu abriu suas portas ao público. Logo após sua inauguração, deu-se início à contratação de equipe para a biblioteca e à formação do acervo com o objetivo de constituir uma coleção especializada em arte, cultura visual, Rio de Janeiro, escravidão e cultura afro-brasileira. O acervo bibliográfico é desenvolvido prioritariamente através de 
doações. Dentre as diversas doações recebidas, destaca-se a coleção de livros de artista, que está entre as maiores coleções institucionais desse tipo de obra do Brasil.

A coleção de livros de artista do MAR teve princípio com a doação de aproximadamente 1200 itens, realizada pelo então diretor cultural e curador do MAR, Paulo Herkenhoff, no final do ano de 2013. Entre os itens dessa coleção, encontram-se as mais variadas tipologias de diferentes nacionalidades de livros de artista.

Antes da coleção de livros de artista chegar ao MAR, Herkenhoff enviou uma lista, organizada pelo próprio, contendo as referências das obras que seriam doadas. Organizada por ordem alfabética de autor, seguida de numeração sequencial, a lista apresenta a seguinte categorização:

a) livros individuais;

b) livros coletivos e revistas de artistas;

c) bibliografias sobre livros de artista e publicações afins;

d) livros ilustrados, capas ou encadernação de artistas, álbuns e livros com gravuras originais, livros de autoria de artistas e tipografia.

Essa relação serviu como primeiro indício de compreensão das intersubjetividades envolvidas na relação entre o sujeito, a instituição e a coleção. Através da lista podemos visualizar as categorias atribuídas ao livro de artista por Herkenhoff e o modo como o sujeito colecionador sistematizou suas obras, bem como podemos iniciar a discussão sobre os desdobramentos e os desafios de uma apropriação institucional da coleção.

\section{O olhar do profissional: uma segunda dimensão intersubjetiva}

Poucos meses após a implantação da biblioteca do MAR veio a notícia da doação da coleção de livros de artista de Paulo Herkenhoff. Até aquele momento, o contato que tínhamos com esse tipo de acervo se limitava a visualizações em vitrines e, portanto, não foi possível mensurar de imediato a importância e a riqueza da experiência que estava por vir.

Inicialmente a coleção doada por Herkenhoff foi encaminhada para a reserva técnica, em um espaço mais consolidado naquele período, já que a biblioteca ainda não havia se estabelecido em um local definitivo. Havia também a dúvida sobre o lugar mais adequado para 
a guarda deste acervo. O critério de definição para o local de guarda foi o tratamento técnico que seria otimizado pelas regras biblioteconômicas, ao passo que dentro dos padrões de descrição museológica o processo é mais moroso devido à necessidade de descrição página a página.

Com a chegada do acervo à biblioteca, uma série de dúvidas relacionadas à forma de acondicionamento, ao modelo de descrição e, principalmente - o que parecia ser o mais difícil -, como identificar um livro de artista (ou seja, compreender o seu conceito para determinar sua tipologia) e como distingui-lo dos demais livros. Embora a coleção de livros de artista tenha chegado ao MAR reunida e devidamente identificada, a dúvida no processo de reconhecimento dessas obras se dava à medida em que observávamos as semelhanças dos livros de artista com os livros tradicionais e nos questionávamos se as obras não poderiam ter sido misturadas sem uma intencionalidade conceitual do colecionador.

A coleção de livros de artista é atualmente (contexto 2013 - 2015) uma das principais componentes do acervo da biblioteca do MAR. Afora as questões que se referem ao tratamento do acervo, para o desenvolvimento de uma coleção, foi preciso reunir os critérios de seleção a serem adotados. Para a elaboração de tais critérios, foi necessário, primeiramente, conhecer as particularidades e especificidades dos itens em questão para, a partir de então, ter o conhecimento necessário para traçar os critérios de seleção e aquisição a serem adotados.

No caso da coleção de livros de artista do MAR, que tem início com a doação de uma coleção pessoal em que todos os itens doados são incorporados ao acervo como livros de artista, foi necessário estudar as características dessas obras para elaborar critérios de seleção para as obras doadas posteriormente por doadores distintos. Conhecer as obras da Coleção Paulo Herkenhoff de livros de artista foi também fundamental para traçar o perfil da coleção e, a partir desse perfil, definir os critérios de seleção que poderiam ser adotados para dar continuidade ao desenvolvimento da coleção de livros de artista pós-coleção fundadora.

Para além da necessidade de conhecimento para a prática do tratamento deste tipo de acervo, conhecer a coleção Paulo Herkenhoff de livros de artista é mergulhar em um universo conceitual elaborado por um dos maiores curadores brasileiros de arte da atualidade. O processo intersubjetivo representa a ação de compreender uma proposta conceitual para determinado tipo de arte, elaborada através da prática da formação de uma coleção. Reconhecer e discutir esta coleção é perceber a objetividade e também a subjetividade do conceito para o colecionador, ou seja, para Herkenhoff. 
O livro de artista compõe acervos comumente encontrados em bibliotecas, mas observamos que as pesquisas desenvolvidas sobre essa temática no âmbito da Biblioteconomia brasileira são pouco frequentes. A maioria dos pesquisadores que se dedicam ao estudo deste tipo de acervo no Brasil são estudiosos de arte, historiadores, críticos de arte e curadores, graduados em artes visuais e história, contemplando mais discussões de natureza conceitual e histórica e menos de organização do conhecimento.

Como pesquisadoras deste tema na área biblioteconômica, encontramos as bibliotecárias da Universidade Federal de Minas Gerais (UFMG), Diná Araújo e Magna dos Santos, cujos trabalhos compreendem os processos técnicos de organização da memória documentária, desde a seleção até o acesso público do item, bem como os cuidados de armazenagem e conservação no espaço da biblioteca.

Fora do Brasil, também não é comum encontrarmos bibliotecários pesquisando livro de artista; contudo, o bibliotecário e curador do MoMA, Clive Phillpot, é um dos grandes colaboradores da Biblioteconomia nos estudos do livro de artista. Os estudiosos da temática que encontramos ao longo desta pesquisa são, em sua maioria, pesquisadores da Arte, o que ressalta a relevância e põe em evidência a importância, no âmbito biblioteconômico, desta investigação.

\section{Impressões no tempo e no espaço intersubjetivo: as terceiras margens para uma reflexão a partir da coleção de livros de artista de Paulo Herkenhoff}

Desde o primeiro contato com o acervo, reconhecemos que entender o que é e como devem ser os processos de catalogação descritiva de seus itens no âmbito de uma biblioteca são abordagens e instrumentos fundamentais para que a Biblioteconomia possa se apropriar dessas análises e, assim, modificar ou acrescentar ao referencial teórico novos elementos que ajudem a melhor identificar, descrever, classificar, conservar e divulgar. Ao longo da pesquisa compreendemos a questão conceitual do livro de artista e o quanto ela interfere no tratamento das obras, bem como em seu local de guarda. Percebemos que a complexidade conceitual do tema interfere diretamente no tratamento do acervo.

A identificação de um livro de artista pode ser tarefa bastante complexa, que varia de acordo com as definições de cada teórico. A abrangência do conceito de livro de artista varia muito de um teórico para outro e o que é considerado livro de artista para um, não 
necessariamente será considerado para o outro. Há ainda as divergências tipológicas. Cada teórico cria suas subcategorias de livro de artista, ao que chamamos também de tipologias; elas variam em suas nomenclaturas e definições. Para a reflexão sobre essas complexidades, os principais teóricos adotados na pesquisa foram Plaza, artista e professora espanhol radicado no Brasil, e Phillpot, em razão da problematização classificatória lançada pelas suas abordagens.

Destacamos também a dificuldade em diferenciar um livro de artista de um livro tradicional. É comum encontrarmos livros de artista em formato de livro tradicional. Por vezes é difícil diferenciar seu conteúdo artístico de um catálogo de arte. Nessa perspectiva se tornou importante eleger um teórico para nortear a identificação dos livros, ou seja, mais uma vez o plano conceitual se colocou como central para o tratamento biblioteconômico. Há ainda a possibilidade de se criar as próprias definições, baseada na teoria e nos princípios institucionais que tangem ao livro de artista.

Além destas questões, como já evidenciado, existem os aspectos ao local de guarda desse tipo de acervo. Por se tratar de livrolobra de arte que remete à forma ou ao conceito daquilo que chamamos de códice vegetal, há um embate sobre qual o espçao de guarda ideal para esse acervo. Visto que se trata (também) de obra de arte, há quem defenda sua guarda exclusivamente em reservas técnicas museológicas; por sua vez, por se tratar (também) de um livro, há quem defenda sua guarda em bibliotecas. Todavia, o que percebemos é que a escolha do local de guarda termina, até o momento, por ser condicionada mais por uma política institucional acrítica, que pode ou não se relacionar com as questões de preservação e integridade do acervo. É importante destacar (novamente) que a premissa inicial do livro de artista é o acesso, é a transposição de espaços fechados, vitrines e demais ambientes em que o acesso não seja possível. Com isso reforçamos a relevância de observar que o local de guarda ofereça acesso aos consulentes, independentemente se biblioteca ou reserva museológica.

O fato identificado até o momento permite-nos apontar, no entanto, que a forma de descrição desses objetos está intrinsecamente ligada ao seu local de guarda, sem uma reflexão complementar e inter-relacionada. Quando em reservas técnicas, são descritas de acordo com os padrões museológicos; quando em bibliotecas a descrição segue padrões biblioteconômicos. A descrição de cada área possui uma abordagem distinta. Enquanto os modelos de representação descritiva da Biblioteconomia aplicados a essa modalidade de obra descrevem o item em sua totalidade (a unidade do recurso), sem grande minúcia; a museologia adota uma uma descrição mais detalhada, em que cada página da obra precisa ser reconhecida. 
Consideramos que, em geral, a descrição museológica atende coerentemente às obras artesanais que, normalmente, apresentam características que podem diferir de uma página para outra, ou seja, possuem mais especificidades. Já a descrição biblioteconômica se aplica de maneira mais objetiva e coerente aos livros produzidos em série, editados através de algum tipo de reprodução mecânica. Isto porque não há necessidade de uma descrição página a página para estes casos. Enfatizamos que ambas as descrições podem atender a essa tipologia de obras, apenas apontamos aqui o que percebemos mais interessante em cada tipo de descrição para livros de artista. No entanto, reconhecendo a complexidade e a dinâmica conceitual por trás da construção e dos modos de apropriação dessas obras, apontamos para a (re)contextualização sempre necessária para cada intervenção classificatória para um dado conjunto de livros de artista.

O acondicionamento do livro de artista também varia, não apenas pelo seu local de guarda, mas também pelo seu formato. Como dito, esse tipo de acervo pode assumir diversas formas que variam desde o formato tradicional do livro até livro em forma de objetos. A forma e o suporte influenciarão diretamente no seu acondicionamento, podendo ser necessários materiais de guarda dos mais diversos, e sua especificidade sempre dependerá do caráter original de cada livro de artista em sua unidade (por exemplo, alguns livros de artista contêm ou são constituídos por resíduos orgânicos).

Deste modo, longe de uma ação local e unicamente pautada em um só plano institucional isolado, a identificação de livros de artista é um processo que demanda a investigação dos modos de elaboração, de apropriação e de intencionalidade (plano objetivamente conceitual) das obras. Identificar quem produziu a obra, em quais contextos, sob o uso de quais técnicas, a partir de qual forma de reprodução, são algumas das questões que precisam ser respondidas para que a identificação e, subsequentemente, a descrição de um livro de artista, sejam feitas. 


\section{Considerações finais: o dilema do livro de artista em seu labirinto}

Com a chegada da coleção de livros de artista à biblioteca do MAR, doada por Paulo Herkenhoff, nos deparamos com um acervo especial, incomum a muitas bibliotecas. Diversas questões relativas aos processos técnicos de organização da memória documentária surgiram, e percebemos o desafio que teríamos pela frente. Assim, como mencionado, iniciamos uma pesquisa exploratória com objetivo de nos familiarizarmos com o novo tipo de acervo e constatamos divergências tipológicas entre os diferentes teóricos do domínio. Verificamos também que grande parte dos estudos relacionados à temática procede de pesquisadores ligados à Arte, o que nos fez perceber a emergência de uma abordagem biblioteconômica.

Estas foram algumas das questões observadas ao longo da primeira etapa da pesquisa na coleção Paulo Herkenhoff de livro de artista do MAR. Acreditamos que a reflexão inicial aqui coloca permita o avanço do processo investigativo que irá subsidiar o tratamento de coleções de livros de artista em diferentes instituições. Concluímos que a definição do que é ou não livro de artista se relaciona diretamente com a escolha de um teórico e sua fundamentação conceitual. Acreditamos na importância da análise de diferentes teorias com a finalidade de selecionar aquela que reflita, em um dado contexto, as demandas de cada coleção, de cada obra.

Observamos, por fim, que o desenvolvimento de uma coleção tem como pedra fundamental a filosofia de cada instituição. Por este motivo, é possível que algumas instituições não se identifiquem plenamente com nenhuma teoria, dado, principalmente, o grau de complexidade e de abertura semântica das noções que envolvem esse domínio. Para estas destacamos que cada instituição pode (re)elaborar seu próprio conceito de livro de artista, desde que em consonância com os planos conceituais e os processos intersubjetivos que estabelecem o significado da obra em seus distintos processos históricos de (re)apropriação. Assim, a conjugação entre as fontes primárias e seus percursos (em nosso caso, o doador e sua trajetória subjetiva com as obras), bem como o olhar teórico que se estabelece na tentativa de demarcação conceitual do livro de artista, advindo do estudo do profissional, tornam-se, igualmente, peças centrais para o labirinto da apropriação de tal "livro" em sua condição híbrida "de artista". 


\section{Referências}

BENTO, S. C. O entre-lugar do livro de artista: a dialética morte-vida na fetichização do livro enquanto suporte. In: CONGRESSO INTERNACIONAL DA ABRALIC: tessituras, intervenções, convergências, 11., 2008, São Paulo. Anais... São Paulo: Universidade de São Paulo, 2008. Não paginado.

ESPÍNOLA, S. Livre como arte: Mostra Internacional do Livro de Artista. In: GOMES, D. C. Núcleo de arte contemporânea da Paraíba: NAC. Rio de Janeiro: FUNARTE, 2004. p. 25 26.

FABRIS, A. O livro de artista: da ilustração ao objeto, O Estado de São Paulo, 19 mar. 1988. Suplemento, p. 6-7. Disponível em:

$<$ http://seminariolivrodeartista.wordpress.com/2009/09/22/o-livro-de-artista-da-ilustracao-aoobjeto/>. Acesso em: 19 nov. 2014.

Memória do patrocínio. [Rio de Janeiro]: [s.n.], 2005. Disponível em:

$<$ http://sites.petrobras.com.br/minisite/memoria/patrocinio_pauloestellita.htm $>$. Acesso em: 10 mar. 2015.

MONTEIRO, A. M. Livro de artista: a arte como projeto. In: SEMINÁRIO NACIONAL DE PESQUISA EM ARTE E CULTURA VISUAL, 4., 2011, Goiânia. Anais... Goiânia: Arte e Cultura Visual, Programa de Pós-Graduação, 2011. p. 26-35. Disponível em:

$<$ http://www.fav.ufg.br/seminariodeculturavisual/Arquivos/2011/Anais-SNAPCV-2011.pdf>. Acesso em: 16 ago. 2014.

MUSEU DE ARTE DO RIO. Museu de Arte do Rio e sua coleção: procedimentos de classificação tipológica da coleção MAR. 2015. Rio de Janeiro, 2015.

PLAZA, J. O livro como forma de arte (I). Arte em São Paulo, São Paulo, n. 6, 1982, Sem paginação. Disponível em:

$<$ http://www.mac.usp.br/mac/expos/2013/julio_plaza/pdfs/o_livro_como_forma_de_arteI.pdf >. Acesso em: 28 nov. 2014.

O livro como forma de arte (II). Arte em São Paulo, São Paulo, n. 7, 1982. Sem paginação. Disponível em:

<http://www.mac.usp.br/mac/expos/2013/julio_plaza/pdfs/o_livro_como_forma_de_arteII.pdf $>$. Acesso em: 28 nov. 2014.

SILVEIRA, P. A crítica e o livro de artista. Pós, Belo Horizonte, v. 2, n. 3, p. 50 - 58, mai. 2012. Disponível em: <https://www.eba.ufmg.br/revistapos/index.php /pos/article/view/35/35>. Acesso em 27 mar. 2017.

A página violada: da ternura à injúria na construção do livro de artista. 2. ed. Porto Alegre: Ed. UFRGS, 2008. 319 p. 